CARTA AL EDITOR

\title{
Error advertido
}

\section{Detected mistake}

\section{Profesor Francisco Rojas Ochoa}

Editor de la Revista Cubana de Salud Pública.

Comunico a ustedes un error de mi autoría en el artículo que se publicó en la Revista Cubana de Salud Pública en 2004 (Rev Cubana Salud Pública 2004;30(1):17-36). En la página 20 del artículo, en el acápite titulado "Relación entre calidad y eficiencia" se señala que en 1999 el Sistema Nacional de Salud de los Estados Unidos (NHS) publicó el llamado "Marco para la evaluación del desempeño" en el que señalan la necesidad de acciones evaluativas en seis áreas:" el error consiste en que esta referencia no es del Sistema Nacional de Salud de los Estados Unidos sino del Reino Unido.

La Dra. Silvia Martínez, leyendo recientemente el artículo, se percató del error y afortunadamente me lo comunicó.

Espero que, aunque algo tarde, esta comunicación sirva para aclaración a los lectores.

Un saludo afectuoso

Rosa Jiménez Paneque Doctora en Ciencias Médicas. Hospital Clinicoquirúrgico "Hermanos Ameijeiras" Correo electrónico: rjimenez@infomed.sld.cu 